This article was originally published in the Elsevier Journal, Chemical Physics, v.326, no.2/3 (2006), p.335-343.

http://www.elsevier.com/wps/find/journaldescription.cws home/505699/description?navopenmen

$\underline{\mathrm{u}}=-2$

doi:10.1016/j.chemphys.2006.02.019

\title{
Theoretical Study of Adducts of Dimethyl Sulfide with Hydroperoxyl and Hydroxyl Radicals
}

\author{
Simone Aloisio* \\ Department of Chemistry , California StateUniversity Channel Islands, \\ Camarillo, California, 91312
}

\begin{abstract}
Structures and energies of complexes of dimethyl sulfide (DMS) with hydroxyl (OH) and hydroperoxyl $\left(\mathrm{HO}_{2}\right)$ radicals have been studied using ab initio and density functional theory. Two isomers of the complex between $\mathrm{OH}$ and DMS were found, one dipoledipole complex and one $3 e^{-} / 2 \mathrm{c}$ complex. The binding energies $\left(\mathrm{D}_{0}\right)$ of these two complexes have been found to be consistent with previous studies. This is the first reported study of the complex between DMS and $\mathrm{HO}_{2}$. One structure was found for this complex, and the binding energy $\left(\mathrm{D}_{0}\right)$ has been determined to be $9.0 \mathrm{kcal} \mathrm{mol}^{-1}$ using the fully optimized MP2/6-311++G(3df,3pd) level of theory. Vibrational and rotational constants are also presented for all of complexes calculated. Thermodynamic parameters and equilibrium constants for the formation of these complexes from the monomers have been calculated. The results have been related to laboratory experiments studying these reactions, and some implications to oxidation of DMS in the atmosphere have been discussed.
\end{abstract}

Author E-mail: simone.aloisio@csuci.edu

One University Drive

Camarillo CA 91320

Phone : (805)437-8999 Fax: (805)437-8895 


\section{Introduction}

Dimethyl sulfide (DMS) is the most abundant naturally occurring sulfur species emitted from oceans ${ }^{1}$. The oxidation of DMS is of particular interest since it may result in the formation of aerosols, and eventually cloud condensation nuclei ${ }^{2}$. The effects of aerosols and clouds remain as the largest uncertainty in climate forecasting today ${ }^{3}$.

Nighttime oxidation of DMS is thought to occur primarily by reaction with nitrate radical $\left(\mathrm{NO}_{3}\right)^{4,5}$. Daytime oxidation of DMS is thought to occur, in large part, via reaction with hydroxyl radical $(\mathrm{OH})^{6-8}$. It has also been shown that DMS is oxidized by chlorine atom, and that this is probably important in the atmosphere ${ }^{9-11}$. DMS oxidation by halogen oxides in the gas phase ${ }^{12-15}$, and via heterogeneous reactions ${ }^{16}$, for example with aqueous phase ozone $\left(\mathrm{O}_{3}\right)^{17,18}$, may also be important. Some model calculations over predict the concentration of DMS in the marine boundary layer (MBL), suggesting that there may be a missing $\operatorname{sink}^{19}$. In addition to looking for a new DMS sink, there has been much interest in examining the reactions that are known sinks for DMS, including reaction with $\mathrm{OH}^{20}$.

There has been renewed interest in the computational study of the reaction of DMS with hydroxyl radical, and specifically on the intermediate complex formed between these two species ${ }^{21-25}$. González-Garcia et al. ${ }^{21}$ have proposed a mechanism with three reaction pathways. Two of the pathways in the proposed mechanism involve the DMS-HO isomer as an intermediate. In one of those pathways, it is proposed that this complex isomerizes to form the DMS-OH complex, which can then further react via an elimination channel. The authors calculate a very small isomerization barrier for the transition state from DMS-HO to DMS-OH, on the order of $1.5 \mathrm{kcal} \mathrm{mol}^{-1}$ on the classical potential energy surface. El-Nahas et al. ${ }^{22}$ have also recently proposed a mechanism for this reaction. Their mechanism has two pathways, one that involves the DMS-HO complex. These authors also calculated the DMS-OH complex, but do not propose that it is an intermediate in the reaction between dimethyl sulfide and hydroxyl radical. Both mechanisms are used to reproduce the experimentally observed branching ratio of the products of the different reaction pathways. El-Nahas et al. ${ }^{22}$ also calculate the rate constant for the DMS $+\mathrm{OH}$ reaction to within an order of magnitude of the experimentally determined value. 
Studies of the reaction between hydroperoxyl radical $\left(\mathrm{HO}_{2}\right)$ and DMS have placed an upper limit ${ }^{26}$ on the rate constant of $5.0 \times 10^{-15} \mathrm{~cm}^{3}$ molecule ${ }^{-1} \mathrm{~s}^{-1}$. However, even though the reaction of $\mathrm{HO}_{2}$ with DMS is much slower than that of $\mathrm{OH}$, because of the much higher concentration of $\mathrm{HO}_{2}$ in the atmosphere, this reaction may still be important. This may be especially true if there is an increase in the rate constant with $\mathrm{O}_{2}$ present, as there is for DMS oxidation by $\mathrm{OH}$. There have been no theoretical studies of the $\mathrm{HO}_{2}+$ DMS reaction. In this work, results of ab initio and density functional calculations are presented examining the complexes of DMS with both $\mathrm{OH}$ and $\mathrm{HO}_{2}$. In the case of $\mathrm{OH}$, this complex may be part of an important reaction path towards the oxidation of DMS, or a so-called pre-reactive complex. In the case of $\mathrm{HO}_{2}$, this is the first theoretical study of a complex with DMS.

\section{Computational Methods}

The optimized geometries, energies, and vibrational frequencies were calculated using the GAUSSIAN $03^{27}$ suite of programs. Structures of the complexes and monomers were optimized using both ab initio and density functional (DFT) methods. $\mathrm{Ab}$ initio optimizations used unrestricted second-order Møller-Plessett ${ }^{28-30}$ perturbation theory (UMP2), while DFT optimizations used the Becke three-parameter ${ }^{31}$ formulation with the Lee-Yang-Parr correlation (B3LYP) ${ }^{32}$ density functional method. Optimizations were attempted using the following basis sets for both ab initio and DFT methods: 6-31G(d), 6-311G(d), 6-311++G(d), 6-311++G(2d,2p), and 6-311++G(3df,3pd). Spin contamination was small for all radicals in this study. Most of the expectation values for the total spin $\left\langle\mathrm{S}^{2}>\right.$ were below 0.77 before annihilation, and approached 0.75 after. The lone exception was the $3 e^{-} / 2 \mathrm{c}$ DMS-OH isomer, which had an initial guess of $\left\langle\mathrm{S}^{2}>\right.$ of 0.79 , but the value was 0.75 after annihilation of the spin contaminant. Spin projected MP2 energies (PMP2) ${ }^{33}$, which other authors ${ }^{22}$ have found to reproduce experimental results for the DMS-OH complex, have also been calculated and are reported.

A single isomer minimum was found for the complex between DMS and $\mathrm{HO}_{2}$ for all methods and levels of theory. The author believes this is the first report of this complex in the literature. There seems to be no analogous complex to the DMS-OH complex, where the oxygen atom of $\mathrm{OH}$ and the sulfur atom of DMS interact. Two 
isomers were calculated for the complex between hydroxyl radical $(\mathrm{OH})$ and dimethyl sulfide (DMS). This is consistent with what has recently been reported ${ }^{21-25}$. One of the complexes is formed by a dipole-dipole interaction between DMS and $\mathrm{OH}$, and is referred to as DMS-HO in this work. This was thought to be the only structure of this complex until another structure, lower energy than the previous, was later found. This latter complex is formed by what is described as a three electron/two center $\left(3 e^{-} / 2 \mathrm{c}\right)^{34}$ interaction, and is referred to as DMS-OH in this work. Local minima were found for both isomers using the DFT methods for geometry optimizations. However, using UMP2 methods with smaller basis sets results in only the dipole-dipole complex, the DMS-HO isomer, being located. In this isomer, the dipole-dipole interaction is between the sulfur atom in DMS and the hydrogen atom in hydroxyl radical. Using the UMP2 method with larger basis sets, only one minimum was found, and this was $3 e^{-} / 2 \mathrm{c}$ isomer, DMS-OH, in which the sulfur atom in DMS is bound to the oxygen atom in hydroxyl radical. This is consistent with what has previously been reported and superbly described ${ }^{21-25}$ in studying the complex between dimethyl sulfide and hydroxyl radical.

Frequency calculations were performed for all structures at the B3LYP/6-311++(3df,3pd) level of theory, with a description for each fundamental vibration. Zero-point energies calculated using these frequencies was used to calculate all of the binding energies $\left(\mathrm{D}_{0}\right)$, regardless of the method used to compute the geometry or energy. Zero-point energies calculated in this way can be assumed to be an upper limit due to the anharmonic nature of the potential energy surface of these complexes. Rotational constants have also been calculated and reported for each geometry optimization.

\section{Results and Discussion}

\section{DMS-HO and DMS-OH}

Two isomers for the complex between dimethyl sulfide and hydroxyl radical have been calculated, and are shown in Figures 1a and 1b. The structures are consistent with those found in previous studies ${ }^{21-25}$. In the two most recent theoretical studies of the reaction mechanism of dimethyl sulfide with hydroxyl radical, the DMS-HO complex is 
involved in the major pathways proposed ${ }^{21,22}$. The DMS-OH complex, while being thermodynamically favored over DMS-HO, is not involved at all in one mechanism ${ }^{22}$, and is in a much slower pathway in the second ${ }^{22}$.

In one of the structures calculated here, DMS-HO, the primary intermolecular interaction is a dipole-dipole interaction between the hydrogen atom in hydroxyl radical and the sulfur atom in dimethyl sulfide. The optimized geometries of the complexes are listed in Table 1. The hydroxyl radical is nearly perpendicular to the C-S-C plane of the dimethyl sulfide. The sulfur atom in DMS and the atoms in the hydroxyl radical are nearly collinear, with an O-H-S bond angle of $149.7^{\circ}$ at the MP2/6-311G(d) level, and $168.1^{\circ}$ at the $\mathrm{B} 3 \mathrm{LYP} / 6-311++\mathrm{G}(3 \mathrm{df}, 3 \mathrm{pd})$ level. The intermolecular bond distance $(R)$, formed between the hydrogen atom in $\mathrm{OH}$ and the sulfur in DMS, is calculated to be $2.475 \AA$ at the MP2/6-311G(d) level and $2.374 \AA$ at the B3LYP/6-311++G(3df,3pd) level. Consistent with other work on dipole-dipole complexes ${ }^{35}$, and on the DMS-HO complex in particular ${ }^{21-25}$, the DFT method predicts a slightly stronger interaction than the MP2 method. This is perhaps best displayed by examining the change in the $\mathrm{O}-\mathrm{H}$ bond length of the hydroxyl radical in the complex as opposed to the isolated monomer. The optimized geometries of the monomers are listed in Table 2. At the B3LYP/6$311++\mathrm{G}(3 \mathrm{df}, 3 \mathrm{pd})$ level, the $\mathrm{O}-\mathrm{H}$ distance in the hydroxyl radical in the isolated monomer is $0.974 \AA$. In the DMS-HO complex, this bond is elongated by $1.2 \%$, to $0.986 \AA$, at the same level of theory. At the MP2/6-311G(d) level, the bond elongation is only about $0.6 \%$, from $0.967 \AA$ to $0.973 \AA$.

The other isomer between dimethyl sulfide and hydroxyl radical, the DMS-OH isomer, has been described as a $3 e^{-} / 2 \mathrm{c}$ complex. In that structure, the hydroxyl radical is again almost perpendicular to the plane formed by the C-S-C skeleton of the dimethyl sulfide. However, in DMS-OH, the oxygen atom in $\mathrm{OH}$ is more closely oriented towards the sulfur atom in DMS, with the hydrogen atom pointing away from the methyl groups of DMS, but at a parallel angle instead of perpendicularly as in DMS-HO. This structure is shown in Figure 1b. Recent work has shown the inadequacy of the B3LYP method for quantitative description of $3 e^{-} / 2 \mathrm{c}$ interactions ${ }^{21}$, so only the MP2 results will be discussed here. Table 1 lists the optimized geometric parameters for the DMS-OH complex. The bond angle between the oxygen atom in $\mathrm{OH}$ and the sulfur and carbon atom in DMS is 
$88.6^{\circ}$ at the MP2/6-311++G(3df,3pd) level of theory. Likewise, the angle between the hydrogen and oxygen atoms in $\mathrm{OH}$ and the sulfur atom in DMS is $103.6^{\circ}$ at the same level of theory, with the dihedral angle between this and a carbon on the DMS calculated to be $130.0^{\circ}$, or in the opposite direction of the methyl groups in DMS. The intermolecular bond distance, $R$, between the oxygen atom in $\mathrm{OH}$ and the sulfur atom in DMS is $2.017 \AA$ at this same level of theory. In contrast to the DMS-HO complex, the intramolecular bond distance in the hydroxyl radical changes little in DMS-OH, from $0.967 \AA$ in the isolated monomer to $0.963 \AA$ in the complex. The intramolecular coordinates in the DMS molecule are more affected by complex formation in the DMS-OH structure, however. The sulfur-carbon bond distance decreases by just over $1 \%$, from $1.804 \AA$ in the isolated monomer to $1.782 \AA$ in the DMS-OH complex. More affected still is the skeletal C-S-C angle in DMS, which is calculated to be $98.4^{\circ}$ in the isolated DMS, but increases to $100.0^{\circ}$ in the DMS-OH complex; an increase of $1.6 \%$.

Rotational constants for the monomers and complexes are listed in Table 3. Both the DMS-HO complex and DMS-OH complex are an asymmetric rotors. With the calculated rotational constants of 5849, 2679, and $2177 \mathrm{MHz}$, the DMS-HO complex, however, is a near oblate rotor, where $\mathrm{A}>\mathrm{B} \approx \mathrm{C}$. The rotational constants for the DMS-HO complex reported here are taken from the B3LYP/6-311++G(3df,3pd) level of theory, which has shown to produce reliable results for optimized structures of complexes formed by dipole-dipole interactions. For the DMS-OH complex, however, the most reliable geometry optimization in this study was at the MP2/6-311++G(3df,3pd) level of theory. Although the DFT method provided a similar structure for this complex, the rotational constants for DMS-OH reported here are taken from the MP2 geometry. This $3 e^{-} / 2 \mathrm{c}$ isomer, in contrast to the dipole complex, is much more like a prolate rotor, where $\mathrm{A} \approx \mathrm{B}<\mathrm{C}$, with rotational constants of 5976, 5797, and $3981 \mathrm{MHz}$. The experimental rotational constants for neither molecule have been reported, although researchers ${ }^{8}$ have reported directly observing the DMS-OH structure via ultraviolet spectroscopy.

Unscaled harmonic vibrational frequencies for the complexes and isolated monomers are listed in Table 4, calculated at the B31YP/6-311++G(3df,3pd) level of theory. For the DMS-HO complex, the $\mathrm{O}-\mathrm{H}$ stretch on the hydroxyl radical is predicted to be red-shifted by $235 \mathrm{~cm}^{-1}$ with respect to the isolated monomer $\mathrm{OH}$. The band 
intensity of this mode is also predicted to increase by a factor of over 30 . This is due to the increased effect of the change in dipole this mode has on the complex relative to the isolated $\mathrm{OH}$. Consistent with the structural changes described above, the intramolecular modes of the dimethyl sulfide are relatively unchanged between the DMS-HO complex and the isolated monomer. There are five new intermolecular fundamental modes for each of the complexes between DMS and OH. For the DMS-HO isomer, the predicted modes at $508 \mathrm{~cm}^{-1}$ and $316 \mathrm{~cm}^{-1}$ have moderately intense band strengths that may be suitable for detection in matrix isolation experiments. For the DMS-OH complex, the hydroxyl radical O-H stretch has a predicted blue-shift of $85 \mathrm{~cm}^{-1}$. The band strength of this mode is predicted to have a larger intensity in the complex than in the monomer by a factor of about 2.5. This is consistent with the shortening of the bond predicted in the geometry optimization. The predicted intensity of this mode is predicted to be a relatively weak infrared absorber, however. Note that both the B3LYP and MP2 geometry optimizations predict similar changes in structure between the monomers and complex for this mode. The intramolecular modes for DMS in this complex are also relatively similar to those of the isolated monomer. There is a noteworthy intermolecular mode predicted at $683 \mathrm{~cm}^{-1}$, with a moderate infrared band strength of $41.0 \mathrm{~km} \mathrm{~mol}^{-1}$. Another intermolecular mode of DMS-OH is predicted at $219 \mathrm{~cm}^{-1}$. It should be noted once more that, these are uncorrected for anharmonicity, which is probably the largest source of error for the intermolecular modes listed. Shifts with respect to the monomers, however, should be less affected by this. There have been no reported experimental gas phase or matrix isolation studies of the vibrational modes of the DMS-OH or DMS-HO isomers of the complex.

The classical well depth (De) and binding energies $\left(\mathrm{D}_{0}\right)$ for the two isomers of the complex between DMS and $\mathrm{OH}$ are listed in Table 5. Binding energies are calculated at $0 \mathrm{~K}$ using the uncorrected harmonic vibrational frequencies listed previously to determine the zero-point energy (ZPE). In addition to the energies reported from the optimized structures using both the DFT (B3LYP) and ab initio (MP2) methods, the spin projected MP2 (PMP2) energies are also reported because other authors have found these to reproduce experimental results for this system. For the DMS-HO isomer, the well depth relative to DMS and $\mathrm{OH}$ was found to be $4.9 \mathrm{kcal} \mathrm{mol}^{-1}$ at the 
B3LYP/6-311++G(3df,3pd) level of theory. This gives a binding energy $\left(D_{0}\right)$ of $3.5 \mathrm{kcal} \mathrm{mol}^{-1}$ when the ZPE is included. This is within $0.2 \mathrm{kcal} \mathrm{mol}^{-1}$ of the best value reported by El-Nahas et al. ${ }^{22}$ The ab initio calculations determine a well depth of $5.4 \mathrm{kcal} \mathrm{mol}^{-1}$ at the UMP2/6-311G(d) level of theory, which is still consistent with the calculations of Gonzalez-Garcia et al. ${ }^{21}$. The PMP2 energies do not differ from the MP2 energies for this isomer. As might be expected, the DFT calculations using the same basis set (B3LYP/6-311G(d)) give a slightly $\mathrm{D}_{\mathrm{e}}, 5.7 \mathrm{kcal} \mathrm{mol}^{-1}$.

The energies for the DMS-OH isomer are much more dependent on the method used. At the B3LYP/6-311++G(3df,3pd) level of theory, $D_{e}$ was calculated to be $14.4 \mathrm{kcal} \mathrm{mol}^{-1}$, and $\mathrm{D}_{0}$ was calculated at $12.1 \mathrm{kcal} \mathrm{mol}^{-1}$. The PMP2 energies, preferred by other authors ${ }^{21}$, give a value of $13.5 \mathrm{kcal} \mathrm{mol}^{-1}$ for $\mathrm{D}_{\mathrm{e}}$ using the largest $(6-311++(3 d f, 3 p d))$ basis set. The fully optimized MP2/6-311++G(3df,3pd) energies calculated are $11.2 \mathrm{kcal} \mathrm{mol}^{-1}$ for $\mathrm{D}_{\mathrm{e}}$, and $8.9 \mathrm{kcal} \mathrm{mol}^{-1}$ for $\mathrm{D}_{0}$.

Experimental results have been obtained for the bond enthalpy $(\Delta \mathrm{H})$ for the DMS-OH isomer. Barone et al. ${ }^{7}$ report this value to be $10.3 \pm 2.5 \mathrm{kcal} \mathrm{mol}^{-1}$ at $298 \mathrm{~K}$, and Hynes et al. ${ }^{8}$ report a bond enthalpy of $13.0 \pm 3.3 \mathrm{kcal} \mathrm{mol}^{-1}$ at $258 \mathrm{~K}$. The change in enthalpy and entropy for the formation of the $3 e^{-} / 2 \mathrm{c}$ complex were calculated so they could be compared to the experimental results obtained previously. At the B3LYP/6-311++G(3df,3pd) level of theory, the bond enthalpy at $298 \mathrm{~K}, \Delta \mathrm{H}(298)$ was calculated to be $12.6 \mathrm{kcal} \mathrm{mol}^{-1}$. Using the PMP2/6-311++G(3df,3pd) energies, $\Delta \mathrm{H}(298)$ was calculated as $11.7 \mathrm{kcal} \mathrm{mol}^{-1}$, while using the UMP2 method with the same basis set results in a value of $9.4 \mathrm{kcal} \mathrm{mol}^{-1}$ for $\Delta \mathrm{H}(298)$. All of these fall within the experimentally determined range of Barone et al. ${ }^{7}$ Using the B3LYP vibrational frequencies, the change in entropy $(\Delta \mathrm{S})$ relative to the isolated monomers was found to be $-27.8 \mathrm{cal} \mathrm{mol}^{-1} \mathrm{~K}^{-1}$. This is very close to the value reported by Barone et al. ${ }^{7}$, which was $-28.4 \pm 6.4 \mathrm{cal} \mathrm{mol}^{-1} \mathrm{~K}^{-1}$, as well as $-27.4 \pm 3.2 \mathrm{cal} \mathrm{mol}^{-1} \mathrm{~K}^{-1}$ reported by Hynes et al. ${ }^{8}$.

Using the thermodynamic values calculated here, the equilibrium constant $\left(\mathrm{K}_{\mathrm{c}}\right)$ for the formation of the DMS-OH complex has been calculated over a range of temperatures, including those at which this complex has been directly observed experimentally. These are reported in Table 6 . The calculated equilibrium constant is 
very sensitive to temperature and binding energy. $\mathrm{K}_{\mathrm{c}}$ was calculated for temperatures ranging from $215 \mathrm{~K}$ to $298 \mathrm{~K}$. It was also calculated using the energies obtained from three methods: B3LYP, MP2, and PMP2, all using the 6-311++G(3df,3pd) basis set. The experimentally determined equilibrium constant was obtained from two different studies $^{7,8}$ at temperatures ranging from $217 \mathrm{~K}$ to $261 \mathrm{~K}$. It was determined using the kinetics of the forward and reverse reactions in both of these studies. For the purposes of this comparison, using the PMP2 energies resulted in replicating the experimental values best. The equilibrium constant calculated using the B3LYP energies were about an order of magnitude larger than experimentally determined $\mathrm{K}_{\mathfrak{c}}$, overestimating even more at the lower temperatures. When $\mathrm{K}_{\mathrm{c}}$ was calculated using the UMP2 method, the results were much lower than the experiments. The PMP2 energies reproduced experimental results relatively well, coming within a factor of three of the higher temperature experiments performed by Hynes et al. ${ }^{8}$, but still coming within a factor of 5, at all but the lowest temperatures when compared to the experiments of Barone et al. ${ }^{7}$.

\section{$\mathrm{DMS}-\mathrm{HO}_{2}$}

One isomer of a complex between dimethyl sulfide and hydroperoxyl radical has been found in this study (Figure 2). In that structure, the primary interaction is a dipoledipole attraction between the hydrogen atom in $\mathrm{HO}_{2}$ and the sulfur atom in DMS. The $\mathrm{H}-\mathrm{O}-\mathrm{O}$ plane is perpendicular to the C-S-C plane of DMS. The structure, shown in Figure 2, is a true minimum, with no imaginary frequencies calculated. There was no complex analogous to the DMS-OH complex found.

The DMS- $\mathrm{HO}_{2}$ geometry was optimized using both the MP2 and DFT method. A similar structure was obtained between these two methods when the same basis set was used. The optimized geometry for this complex is reported in Table 1 from the calculations using the largest basis set, $6-311++\mathrm{G}(3 \mathrm{df}, 3 \mathrm{pd})$. There is generally good agreement between the structures calculated using the different methods. The intermolecular bond distance, $R$, between the hydrogen atom in $\mathrm{HO}_{2}$ and the sulfur atom in DMS, is calculated to be $2.200 \AA$ at the B3LYP/6-311++G(3df,3pd) level of theory, and $2.152 \AA$ at the MP2/6-311++G(3df,3pd) level. This is about $2 \%$ shorter than the 
DMS-HO complex, which also is a dipole-dipole interaction, calculated at the same DFT level of theory. As in the complex with hydroxyl radical, the intermolecular angle formed between the sulfur atom in DMS and the hydrogen and oxygen atoms in $\mathrm{HO}_{2}$, labeled O-H-S in Table 1, is nearly linear. This angle is calculated to be $162.5^{\circ}$ and $166.2^{\circ}$ using the MP2 and B3LYP methods, respectively.

Intramolecular coordinates can be compared to those in the isolated monomers, listed in Table 2. The $\mathrm{H}-\mathrm{O}$ bond distance in $\mathrm{HO}_{2}$ is slightly elongated as a result of being in a complex, by about $0.5 \%$ at both levels of theory. Also, the H-O-O bond angle is only slightly sharper, by about $0.2 \%$ at both levels of theory. As in the DMS-HO complex, the intramolecular DMS coordinates do not seem to be significantly affected as a result of complex formation in DMS- $\mathrm{HO}_{2}$.

Rotational constants for the DMS- $\mathrm{HO}_{2}$ complex are listed in Table 3. The rotational constants are $4859 \mathrm{MHz}, 1848 \mathrm{MHz}$, and $1688 \mathrm{MHz}$, labeled A, B, and C for the B3LYP/6-311++G(3df,3pd) structure. Like the DMS-HO complex, the $\mathrm{DMS}^{-\mathrm{HO}_{2}}$ complex is a near-oblate rotor with $\mathrm{A}>\mathrm{B} \approx \mathrm{C}$.

Vibrational frequencies for the DMS- $\mathrm{HO}_{2}$ complex and the isolated monomers are listed in Table 4, calculated using the B3LYP/6-311++G(3df,3pd) level of theory. Consistent with the optimized geometric parameters, the most affected vibrational frequency is the $\mathrm{O}-\mathrm{H}$ stretch in $\mathrm{HO}_{2}$. This mode is predicted to have a $433 \mathrm{~cm}^{-1}$ red-shift as a result of the elongation of that coordinate in the DMS- $\mathrm{HO}_{2}$ complex. The band strength of this mode is also predicted to increase by a factor of over 40 times in the complex with respect to isolated $\mathrm{HO}_{2}$. The other two hydroperoxyl radical modes, the $\mathrm{H}-\mathrm{O}-\mathrm{O}$ bend and the O-O stretch, are also significantly shifted as a result of complex formation. The bend has a predicted blue-shift of $93 \mathrm{~cm}^{-1}$, while the O-O stretch also has a predicted blue shift of $23 \mathrm{~cm}^{-1}$. The band strength of these modes is predicted to decrease in intensity, to $65 \%$ and $56 \%$ respectively, of the analogous bands in isolated $\mathrm{HO}_{2}$. The intramolecular modes of DMS are very similar to those of isolated DMS, consistent with the relatively small change in geometry of DMS in the complex. There are six new intermolecular vibrational modes in the complex. The highest in frequency are also predicted to be the strongest absorbers. There is a moderately strongly absorbing band predicted at $632 \mathrm{~cm}^{-1}$, and another moderately weak absorbing band predicted at 
$212 \mathrm{~cm}^{-1}$. The remaining four fundamental intermolecular modes are predicted to be in the far-infrared region and also to be weak or very weak absorbing modes.

The relative energies for the DMS- $\mathrm{HO}_{2}$ complex are listed in Table 5. Using the B3LYP/6-311++G(3df,3pd) method, $D_{\mathrm{e}}$ was calculated to be $8.0 \mathrm{kcal} \mathrm{mol}^{-1}$. Adding the zero-point correction calculated at this level of theory, $\mathrm{D}_{0}$ is $6.6 \mathrm{kcal} \mathrm{mol}^{-1}$. The MP2 method calculates a more strongly bound complex, with a $\mathrm{D}_{\mathrm{e}}$ of $10.4 \mathrm{kcal} \mathrm{mol}^{-1}$ and a $\mathrm{D}_{0}$ of $9.0 \mathrm{kcal} \mathrm{mol}^{-1}$ at the MP2/6-311++G(3df,3pd) level of theory. The spin-projected PMP2 energies were nearly identical to the MP2 energies for the DMS- $\mathrm{HO}_{2}$ complex. The energies calculated at MP2/6-311++G(3df,3pd) level of theory are used to calculate reported enthalpy values for this complex. The intermolecular bond enthalpy, $\Delta H(298)$, was calculated to be $9.0 \mathrm{kcal} \mathrm{mol}^{-1}$. Using the lower binding energy calculated at the B3LYP/6-311++G(3df,3pd) level of theory, $\Delta \mathrm{H}(298)$ was calculated to be $5.2 \mathrm{kcal} \mathrm{mol}^{-1}$. Based on the comparison to experimental values for the DMS-OH complex, this value is probably a lower limit. Entropy (S) values calculated using the DFT method agreed quite well with experiment. Using the frequencies calculated at the B3LYP/6-311++G(3df,3pd) level of theory, $\Delta \mathrm{S}$ for the formation of the complex is $-28.32 \mathrm{cal} \mathrm{mol}^{-1} \mathrm{~K}^{-1}$. Comparing MP2 and B3LYP computed values of $\Delta \mathrm{S}$ using a smaller basis set $(6-31 \mathrm{G}(\mathrm{d}))$ yield values within $0.2 \mathrm{cal} \mathrm{mol}^{-1} \mathrm{~K}^{-1}$.

From these thermodynamic parameters, $\mathrm{K}_{\mathrm{c}}$ for the formation of the DMS- $\mathrm{HO}_{2}$ complex was calculated for the temperature range $215 \mathrm{~K}-298 \mathrm{~K}$, and is listed in Table 7 . There is no experimental data to compare for this complex. Included in the table are value for $\mathrm{K}_{\mathrm{c}}$ that are scaled based on the comparison to experimental results for the DMS-OH complex. The scaling factor used was $1 / 3$ of the raw calculated value. The equilibrium constant for DMS- $\mathrm{HO}_{2}$ is calculated to be several times smaller than that for the DMS-OH complex. For example, at $250 \mathrm{~K}$, the experimentally derived $\mathrm{K}_{\mathrm{c}}$ for formation of the DMS-OH complex is $2.82 \times 10^{-17} \mathrm{~cm}^{3}$ molecule ${ }^{-1}$. For the $\mathrm{DMS}^{-} \mathrm{HO}_{2}$ complex, the calculated value at this same temperature is $1.5 \times 10^{-19} \mathrm{~cm}^{3}$ molecule ${ }^{-1}$ without any scaling. The scaled value at $250 \mathrm{~K}$ is, $4.9 \times 10^{-20} \mathrm{~cm}^{3}$ molecule-1. Under most experimental and atmospheric conditions, it is predicted that the $\mathrm{DMS}-\mathrm{HO}_{2}$ has a low number density. However, because of the high number density of $\mathrm{HO}_{2}$ with respect 
to $\mathrm{OH}$, the number density of the complex is on the same order of magnitude as the DMS-OH complex.

\section{Conclusions}

Results of theoretical calculations of the complexes of DMS with $\mathrm{OH}$ and $\mathrm{HO}_{2}$ have been presented. Two isomers have been located, DMS-OH and DMS-HO, for the complex with hydroxyl radical. These results are found to be consistent with both recent theoretical studies and results derived from experiments. The equilibrium constant for the DMS-OH isomer has been calculated and is within an order of magnitude of what is observed experimentally. Similar calculations have been performed for the complex between DMS and $\mathrm{HO}_{2}$. The DMS- $\mathrm{HO}_{2}$ complex has a lower binding energy than the DMS-OH complex, the stronger of the two isomers for hydroxyl radical. This results in a much smaller equilibrium constant for formation. The DMS- $\mathrm{HO}_{2}$ complex probably does not form in significant amounts under experimental conditions. For example, if $\left[\mathrm{HO}_{2}\right]=1 \times 10^{11}$ molecules $\mathrm{cm}^{-3}$ and $[\mathrm{DMS}]=1 \times 10^{16}$ molecules $\mathrm{cm}^{-3}$, the concentration of DMS- $-\mathrm{HO}_{2}$ would be just $5 \times 10^{7}$ molecule $\mathrm{cm}^{-3}$ at $250 \mathrm{~K}$. In the atmosphere, concentrations of DMS and $\mathrm{HO}_{2}$ are orders of magnitude smaller than these.

It may be possible that $\mathrm{DMS}-\mathrm{HO}_{2}$ reacts with molecular oxygen, in the same way that is proposed for the complex between DMS and $\mathrm{OH}$. Two possible reaction products of this might be hydrogen peroxide $\left(\mathrm{H}_{2} \mathrm{O}_{2}\right)$ and dimethyl sulfide radical $\left(\mathrm{CH}_{2} \mathrm{SCH}_{3}\right)$, or dimethyl sulfoxide $\left(\mathrm{CH}_{3} \mathrm{~S}(\mathrm{O}) \mathrm{CH}_{3}\right)$ and hydroxyl radical. The former would constitute a hydrogen abstraction by $\mathrm{HO}_{2}$, and is endothermic by about $6.2 \mathrm{kcal} \mathrm{mol}^{-1}$. The latter is exothermic by about $20.5 \mathrm{kcal} \mathrm{mol}^{-1}$, but would probably require a large activation. It may be worth further investigation however, given the importance of DMS oxidation and the discrepancy between models and measurements. No low temperature experiments have been performed on the reaction of $\mathrm{HO}_{2}$ with DMS. 


\section{References}

(1) B.J. Finlayson-Pitts, J.N. Pitts, Chemistry of the Upper and Lower Atmosphere, Academic Press, San Diego, 1999.

(2) R.J. Charlson, J.E. Lovelock, M.O. Andreae, S.G. Warren, Nature 326 (1987) 655661.

(3) J.T. Houghton, Y. Ding, D.J. Griggs, M. Noguer, P.J. van der Linden, D. Xiaosu, K. Maskell, C.A. Johnson, Climate Change 2001: The Scientific Basis; Contribution of Working Group I to the Third Assessment Report of the Intergovernmental Panel on Climate Change (IPCC); Cambridge University Press: New York, 2001; (ISBN: $05210149562001)$.

(4) T.J. Wallington, R. Atkinson, A.M. Winer, J.N. Pitts, J. Phys. Chem. 90 (1986) 46404644.

(5) E.J. Dlugokencky, C.J. Howard, J. Phys. Chem. 92 (1988) 1188-1193.

(6) A.J. Hynes, P.H. Wine, D.H. Semmes, J. Phys. Chem. 90 (1986) 4148-4156.

(7) S.B Barone, A.A. Turnipseed, A.R. Ravishankara, J. Phys. Chem. 100 (1996) 1469414702.

(8) A.J. Hynes, R.B. Stoker, A.J. Pounds, T. McKay, J.D. Bradshaw, J.M. Nicovich, P.H. Wine, J. Phys. Chem. 99 (1995) 16967-16975.

(9) R.E. Stickel, J.M. Nicovich, S. Wang, Z. Zhao, P.H. Wine, J. Phys. Chem. 96 (1992) 9875-9883.

(10) D.J. Kinnison, W. Mengon, J.A. Kerr, J. Chem. Soc. Faraday Trans. 92 (1996) 369372.

(11) L. Zhu, J.M. Nicovich, P.H. Wine, J. Phys. Chem. A 109 (2005) 3903-3911.

(12) Y.U. Bedjanian, G. Poulet, G. Le Bras, Int. J. Chem. Kinet. 28 (1996) 383-389.

(13) T. Ingham, D. Bauer, R. Sander, P.J. Crutzen, J.N. Crowley, J. Phys. Chem. A 103 (1999) 7199-7209.

(14) Y. Nakano, M. Goto, S. Hashimoto, M. Kawasaki, T.J. Wallington, J. Phys. Chem. A 105 (2001) 11045-11050.

(15) Y. Nakano, S. Enami, S. Nakamichi, S. Aloisio, S. Hashimoto, M. Kawasaki, J. Phys. Chem. A 107 (2003) 6381-6387.

(16) R. Von Glasow, P.J. Crutzen, Atmospheric Chemistry and Physics 4 (2004) 589608. 
(17) Y.N. Lee, and X.J. Zhou, J. Geophys. Res. 99 (1994) 3597-3605.

(18) M. Gershenzon, P. Davidovits, J.T. Jayne, C.E. Kolb, D.R. Worsnop, J.Phys. Chem. A $105(2001) 7031-7036$.

(19) J.D. James, R.M. Harrison, N.H. Savage, A.G. Allen, J.L. Grenfell, B.J. Allan, J.M.C. Plane, C.N. Hewitt, B. Davison, L. Robertson, J. Geophys. Res. 105 (2000) 26379-26392.

(20) M.B. Williams, P. Campuzano-Jost, D. Bauer, A.J. Hynes, Chem. Phys. Lett. 34 (2001) 61-67.

(21) N. González-Garcia, A. González-LaFont, J.M. Lluch, J. Comp. Chem. 26 (2005) $569-583$

(22) A.M. El-Nahas, T. Uchimaru, S. Masaaki, K. Tokuhashi, A. Sekiya, J. Molec. Struct: THEOCHEM 722 (2005) 9-19.

(23) T. Uchimaru, S. Tsuzuki, M. Sugie, K. Tokuhashi, A. Sekiya, Chem. Phys. Lett. 408 (2005) 216-220.

(24) L. Wang, and J. Zhang, J. Molec. Struct.: THEOCHEM 543 (2001) 167-175.

(25) A. Gross, I. Barnes, R.M. Sørenson, J. Kongsted, K.V. Mikkelsen, J. Phys. Chem. A 108 (2004) 8659-8671.

(26) A. Mellouki, and A.R. Ravishankara, Int. J. Chem. Kinet. 26 (1994) 355-365.

(27) Gaussian 03, Revision B.02, Frisch, M. J.; Trucks, G. W.; Schlegel, H. B.; Scuseria, G. E.; Robb, M. A.; Cheeseman, J. R.; Montgomery, Jr., J. A.; Vreven, T.; Kudin, K. N.; Burant, J. C.; Millam, J. M.; Iyengar, S. S.; Tomasi, J.; Barone, V.; Mennucci, B.; Cossi, M.; Scalmani, G.; Rega, N.; Petersson, G. A.; Nakatsuji, H.; Hada, M.; Ehara, M.; Toyota, K.; Fukuda, R.; Hasegawa, J.; Ishida, M.; Nakajima, T.; Honda, Y.; Kitao, O.; Nakai, H.; Klene, M.; Li, X.; Knox, J. E.; Hratchian, H. P.; Cross, J. B.; Bakken, V.; Adamo, C.; Jaramillo, J.; Gomperts, R.; Stratmann, R. E.; Yazyev, O.; Austin, A. J.; Cammi, R.; Pomelli, C.; Ochterski, J. W.; Ayala, P. Y.; Morokuma, K.; Voth, G. A.; Salvador, P.; Dannenberg, J. J.; Zakrzewski, V. G.; Dapprich, S.; Daniels, A. D.; Strain, M. C.; Farkas, O.; Malick, D. K.; Rabuck, A. D.; Raghavachari, K.; Foresman, J. B.; Ortiz, J. V.; Cui, Q.; Baboul, A. G.; Clifford, S.; Cioslowski, J.; Stefanov, B. B.; Liu, G.; Liashenko, A.; Piskorz, P.; Komaromi, I.; Martin, R. L.; Fox, D. J.; Keith, T.; Al-Laham, M. A.; Peng, C. Y.; Nanayakkara, A.; Challacombe, M.; Gill, P. M. W.; Johnson, B.; Chen, W.; Wong, M. W.; Gonzalez, C.; and Pople, J. A.; Gaussian, Inc., Wallingford CT, 2004.

(28) C. Møller, M.S. Plesset, Phys. Rev. 46 (1934) 618.

(29) M. Head-Gordan, J.A. Pople, M.J. Frisch, Chem. Phys. Lett. 153 (1988) 503-506. 
(30) M. Head-Gordan, and T. Gordan-Head, Chem. Phys. Lett. 220 (1994) 122-128.

(31) A.D. Becke, J. Chem. Phys. 98 (1993) 1372-1377.

(32) C. Lee, W. Yang, R.G. Parr, Phys. Rev. B 41 (1988) 785.

(33) H.B. Schlegel, J. Phys. Chem. 92 (1988) 3075-3078.

(34) I. Fourrè and J. Bergés, J. Phys. Chem. A 108 (2004) 898-906.

(35) S. Aloisio and J.S. Francisco, J. Phys. Chem. A 102 (1998) 1899-1902. 


\section{Figure Captions}

Figure 1a: Structure of the DMS-OH Complex

Figure 1b: Structure of the DMS-HO Complex

Figure 2: Structure of the DMS- $\mathrm{HO}_{2}$ Complex 


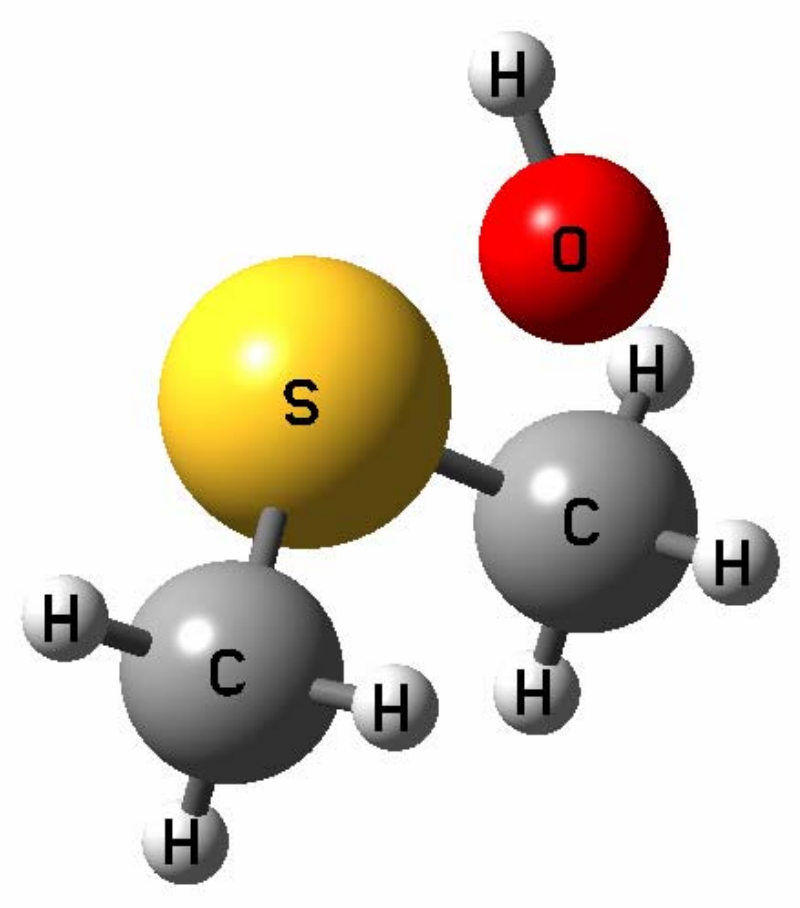

Figure 1a 


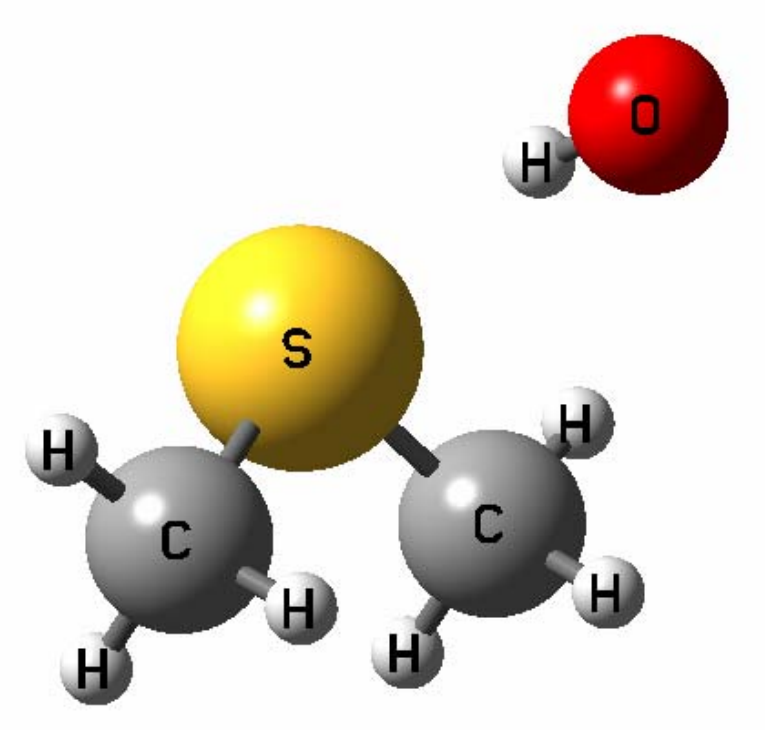

Figure 1b 


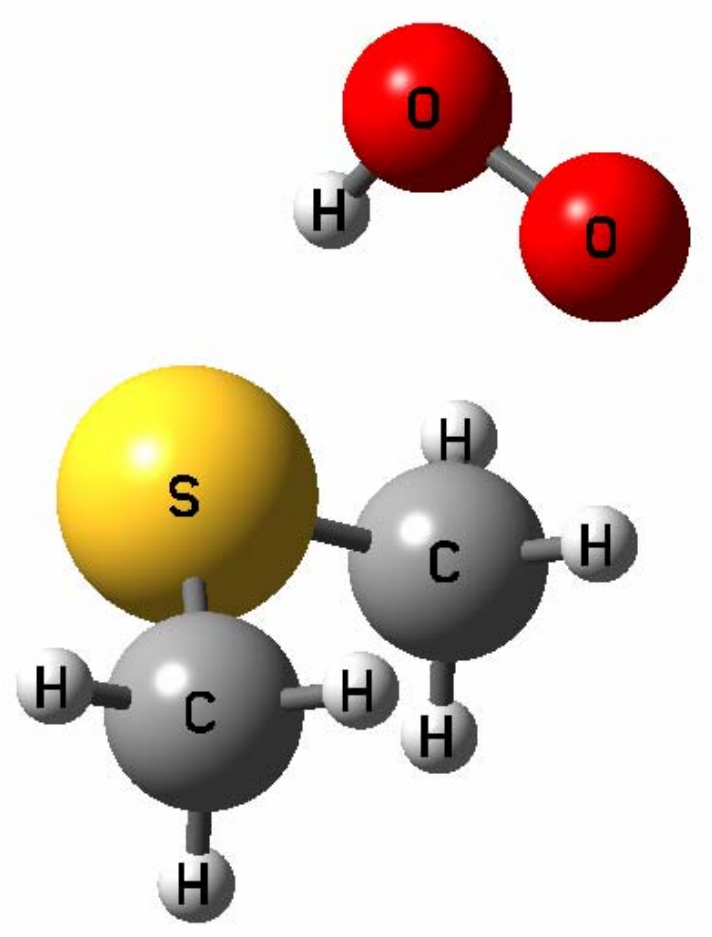

Figure 2 
Table 1. Optimized Geometries of Complexes at the Highest Level of Theory

\begin{tabular}{|c|c|c|c|c|c|c|c|}
\hline \multirow[t]{2}{*}{ Molecule/Coordinate } & \multirow[t]{2}{*}{ Type/Coordinate } & \multicolumn{2}{|c|}{ DMS-OH } & \multicolumn{2}{|c|}{ DMS-HO } & \multicolumn{2}{|c|}{ DMS- $-\mathrm{HO}_{2}$} \\
\hline & & $\mathrm{UMP}^{\mathrm{a}}{ }^{\mathrm{a}}$ & $\mathrm{B} 3 \mathrm{LYP}^{\mathrm{a}}$ & $\mathrm{UMP}^{\mathrm{b}}$ & B3LYP $^{\mathrm{a}}$ & $\mathrm{UMP}^{\mathrm{a}}$ & B3LYP ${ }^{\mathrm{a}}$ \\
\hline Intermolecular & $R$ & 2.017 & 2.298 & 2.475 & 2.374 & 2.152 & 2.200 \\
\hline \multirow[t]{9}{*}{ Coordinates } & HOS & 103.6 & 99.6 & & & & \\
\hline & OSC & 88.6 & 88.4 & & & & \\
\hline & OHS & & & 149.7 & 168.1 & 162.5 & 166.2 \\
\hline & $\mathrm{HSC}$ & & & 86.3 & 100.5 & 93.7 & 96.5 \\
\hline & HOSC & 130.0 & 129.5 & & & & \\
\hline & $\mathrm{OSCH}$ & 87.5 & 90.4 & & & & \\
\hline & OHSC & & & 49.3 & 51.3 & 49.5 & 50.6 \\
\hline & $\mathrm{HSCH}$ & & & 93.8 & 76.6 & 83.5 & 90.0 \\
\hline & OOHS & & & & & 0.0 & 0.0 \\
\hline Radical & $\mathrm{HO}$ & 0.963 & 0.966 & 0.973 & 0.986 & 0.993 & 0.998 \\
\hline \multirow[t]{2}{*}{ Coordinates } & $\mathrm{OO}$ & & & & & 1.302 & 1.324 \\
\hline & $\mathrm{HOO}$ & & & & & 103.9 & 104.7 \\
\hline DMS & $\mathrm{SC}$ & 1.782 & 1.802 & 1.806 & 1.814 & 1.799 & 1.815 \\
\hline \multirow[t]{20}{*}{ Coordinates } & $\mathrm{SC}$ & 1.782 & 1.802 & 1.806 & 1.814 & 1.799 & 1.815 \\
\hline & $\mathrm{HC}$ & 1.086 & 1.087 & 1.091 & 1.088 & 1.087 & 1.088 \\
\hline & $\mathrm{HC}$ & 1.086 & 1.087 & 1.091 & 1.088 & 1.087 & 1.088 \\
\hline & $\mathrm{HC}$ & 1.087 & 1.089 & 1.091 & 1.088 & 1.088 & 1.088 \\
\hline & $\mathrm{HC}$ & 1.086 & 1.087 & 1.091 & 1.088 & 1.087 & 1.088 \\
\hline & $\mathrm{HC}$ & 1.086 & 1.087 & 1.091 & 1.088 & 1.087 & 1.088 \\
\hline & $\mathrm{HC}$ & 1.087 & 1.089 & 1.091 & 1.088 & 1.088 & 1.088 \\
\hline & $\mathrm{CSC}$ & 100.0 & 100.8 & 98.2 & 100.4 & 98.7 & 100.3 \\
\hline & HCS & 107.3 & 107.0 & 107.6 & 106.9 & 107.4 & 107.0 \\
\hline & $\mathrm{HCS}$ & 107.9 & 108.9 & 111.0 & 111.1 & 110.1 & 110.7 \\
\hline & $\mathrm{HCS}$ & 109.9 & 110.4 & 110.9 & 110.6 & 110.1 & 110.3 \\
\hline & $\mathrm{HCS}$ & 107.3 & 107.0 & 107.6 & 106.9 & 107.4 & 107.0 \\
\hline & $\mathrm{HCS}$ & 107.9 & 108.9 & 111.0 & 111.1 & 110.1 & 110.7 \\
\hline & HCS & 109.9 & 110.4 & 110.9 & 110.6 & 110.1 & 110.3 \\
\hline & HCSC & 175.5 & 178.5 & 179.4 & 178.9 & 177.8 & 178.8 \\
\hline & $\mathrm{HCSC}$ & 57.8 & 60.4 & 60.4 & 60.0 & 58.6 & 59.8 \\
\hline & HCSC & -64.6 & -62.3 & -62.0 & -62.5 & -63.4 & -62.7 \\
\hline & HCSC & 184.3 & 181.5 & 180.6 & 181.1 & 182.2 & 181.2 \\
\hline & $\mathrm{HCSC}$ & -57.8 & -60.4 & -60.4 & -60.0 & -58.6 & -59.8 \\
\hline & $\mathrm{HCSC}$ & 64.6 & 62.3 & 62.0 & 62.5 & 63.4 & 62.7 \\
\hline
\end{tabular}

All bond lengths are reported in Ångstroms and bond angles are in degrees

${ }^{a}$ Basis set is $6-311++\mathrm{G}(3 \mathrm{df}, 3 \mathrm{pd})$

${ }^{\mathrm{b}}$ Basis set is 6-311G(d)

Table 2. Optimized Geometries of Monomers at Selected Levels of Theory

\begin{tabular}{lllccc} 
Molecule & Type & Coordinate & UMP2 & UMP2 & B3LYP \\
\cline { 4 - 6 } & & & $6-311 \mathrm{G}(\mathrm{d})$ & $6-311++\mathrm{G}(3 \mathrm{df}, 3 \mathrm{pd})$ & $6-311++\mathrm{G}(3 \mathrm{df}, 3 \mathrm{pd})$ \\
\hline $\mathrm{OH}$ & $R \mathrm{n}$ & $\mathrm{OH}$ & 0.967 & 0.967 & 0.974 \\
$\mathrm{HO}_{2}$ & $R \mathrm{n}$ & $\mathrm{HO}$ & & 0.970 & 0.975
\end{tabular}




\begin{tabular}{|c|c|c|c|c|c|}
\hline \multirow[t]{3}{*}{ Molecule } & \multirow{3}{*}{$\begin{array}{l}\text { Type } \\
R \mathrm{n} \\
\text { An }\end{array}$} & \multirow{3}{*}{$\begin{array}{l}\text { Coordinate } \\
\text { OO } \\
\text { HOO }\end{array}$} & \multirow[t]{2}{*}{ UMP2 } & \multirow{2}{*}{$\begin{array}{c}\text { UMP2 } \\
1.319\end{array}$} & \multirow{2}{*}{$\frac{\text { B3LYP }}{1.324}$} \\
\hline & & & & & \\
\hline & & & & 104.7 & 105.6 \\
\hline \multirow[t]{21}{*}{ DMS } & $R \mathrm{n}$ & $\mathrm{SC}$ & 1.804 & 1.797 & 1.813 \\
\hline & $R \mathrm{n}$ & $\mathrm{SC}$ & 1.804 & 1.797 & 1.813 \\
\hline & $R \mathrm{n}$ & $\mathrm{HC}$ & 1.091 & 1.087 & 1.088 \\
\hline & $R \mathrm{n}$ & $\mathrm{HC}$ & 1.092 & 1.088 & 1.089 \\
\hline & $R \mathrm{n}$ & $\mathrm{HC}$ & 1.092 & 1.088 & 1.089 \\
\hline & $R \mathrm{n}$ & $\mathrm{HC}$ & 1.091 & 1.087 & 1.088 \\
\hline & $R \mathrm{n}$ & $\mathrm{HC}$ & 1.092 & 1.088 & 1.089 \\
\hline & $R \mathrm{n}$ & $\mathrm{HC}$ & 1.092 & 1.088 & 1.089 \\
\hline & An & $\mathrm{CSC}$ & 98.4 & 98.3 & 99.9 \\
\hline & An & HCS & 107.6 & 107.5 & 107.0 \\
\hline & An & HCS & 111.3 & 110.8 & 111.1 \\
\hline & An & HCS & 111.3 & 110.8 & 111.1 \\
\hline & An & HCS & 107.6 & 107.5 & 107.0 \\
\hline & An & HCS & 111.3 & 110.8 & 111.2 \\
\hline & An & HCS & 111.3 & 110.8 & 111.1 \\
\hline & $D n$ & HCSC & 180.0 & 180.0 & 180.0 \\
\hline & $D \mathrm{n}$ & HCSC & 61.3 & 61.1 & 61.3 \\
\hline & Dn & HCSC & -61.2 & -61.1 & -61.3 \\
\hline & $D \mathrm{n}$ & HCSC & 180.0 & 180.0 & 180.0 \\
\hline & Dn & HCSC & 61.3 & 61.1 & 61.3 \\
\hline & $D n$ & HCSC & -61.2 & -61.1 & -61.3 \\
\hline
\end{tabular}

All bond lengths are reported in Ångstroms and angles are in degrees.

$R n$ designates a bond length, $A n$ a bond angle, and $D n$ a dihedral angle. 
Table 3. Rotational Constants for Monomers and Complexes

\begin{tabular}{|c|c|c|c|c|c|c|}
\hline \multirow[t]{2}{*}{ Molecule/Coordinate } & \multicolumn{3}{|c|}{ B3LYP $^{a}$} & \multicolumn{3}{|c|}{$\mathrm{MP}^{\mathrm{b}}$} \\
\hline & $A$ & $B$ & C & $A$ & $B$ & $C$ \\
\hline $\mathrm{OH}$ & 561382 & 561382 & & 570538 & 570538 & \\
\hline $\mathrm{HO}_{2}$ & 623027 & 33919 & 32167 & 623777 & 34859 & 33014 \\
\hline DMS & 17972 & 7462 & 5650 & 17755 & 7760 & 5796 \\
\hline DMS-OH ${ }^{\mathrm{a}}$ & 5762 & 4902 & 3507 & 5976 & 5797 & 3981 \\
\hline DMS-HO & 5849 & 2679 & 2177 & $5722^{c}$ & $3026^{c}$ & $2477^{\mathrm{c}}$ \\
\hline $\mathrm{DMS}^{-\mathrm{HO}_{2}}$ & 4859 & 1848 & 1688 & 4972 & 2009 & 1841 \\
\hline
\end{tabular}

All rotational constants are reported in $\mathrm{MHz}$

${ }^{a}$ Rotational constants for the optimized B3LYP/6-311++G(3df,3pd) structures

${ }^{\mathrm{b}}$ Rotational constants for the optimized at the MP2/6-311++G(3df,3pd) structures

${ }^{c}$ Rotational constants for the optimized at the MP2/6-311G(d) structures 
Table 4. Calculated Vibrational Frequencies for Monomers and Complexes

\begin{tabular}{|c|c|c|c|c|c|c|c|c|c|c|c|c|c|}
\hline \multirow[t]{2}{*}{ Radical/DMS/Modes } & \multirow[t]{2}{*}{ Mode } & \multicolumn{2}{|c|}{$\mathrm{OH}$} & \multicolumn{2}{|c|}{$\mathrm{HO}_{2}$} & \multicolumn{2}{|c|}{ DMS } & \multicolumn{2}{|c|}{ DMS-OH } & \multicolumn{2}{|c|}{ DMS-HO } & \multicolumn{2}{|c|}{ DMS- $\mathrm{HO}_{2}$} \\
\hline & & Freq & Int & Freq & Int & Freq & Int & Freq & Int & Freq & Int & Freq & Int \\
\hline Radical & $\begin{array}{l}\mathrm{OH} \\
\text { stretch }\end{array}$ & 3711 & 12.4 & 3604 & 24.0 & & & 3796 & 31.5 & 3476 & 432.8 & 3171 & 962.3 \\
\hline \multirow[t]{2}{*}{ Modes } & $\begin{array}{l}\text { HOO } \\
\text { bend }\end{array}$ & & & 1435 & 39.5 & & & & & & & 1528 & 25.6 \\
\hline & $\begin{array}{l}\text { OO } \\
\text { stretch }\end{array}$ & & & 1172 & 27.2 & & & & & & & 1195 & 15.3 \\
\hline DMS & $\begin{array}{l}\mathrm{CH} \\
\text { stretch }\end{array}$ & & & & & 3126 & 2.5 & 3149 & 0.4 & 3135 & 0.8 & 3137 & 0.7 \\
\hline \multirow[t]{20}{*}{ Modes } & $\begin{array}{l}\mathrm{CH} \\
\text { stretch }\end{array}$ & & & & & 3125 & 11.2 & 3148 & 2.7 & 3134 & 7.7 & 3136 & 7.7 \\
\hline & $\begin{array}{l}\mathrm{CH} \\
\text { stretch }\end{array}$ & & & & & 3106 & 0.0 & 3134 & 0.6 & 3120 & 0.0 & 3129 & 0.1 \\
\hline & $\begin{array}{l}\mathrm{CH} \\
\text { stretch }\end{array}$ & & & & & 3098 & 26.0 & 3132 & 3.9 & 3114 & 13.8 & 3123 & 2.0 \\
\hline & $\begin{array}{l}\mathrm{CH} \\
\text { stretch }\end{array}$ & & & & & 3031 & 30.3 & 3046 & 13.0 & 3041 & 20.2 & 3045 & 18.3 \\
\hline & $\begin{array}{l}\mathrm{CH} \\
\text { stretch }\end{array}$ & & & & & 3028 & 34.5 & 3045 & 19.9 & 3038 & 25.7 & 3041 & 23.8 \\
\hline & $\begin{array}{l}\mathrm{HC} \\
\text { bend }\end{array}$ & & & & & 1487 & 0.6 & 1477 & 10.7 & 1487 & 1.4 & 1487 & 5.7 \\
\hline & $\begin{array}{l}\mathrm{HC} \\
\text { bend }\end{array}$ & & & & & 1480 & 16.7 & 1467 & 9.4 & 1478 & 17.2 & 1479 & 12.1 \\
\hline & $\begin{array}{l}\mathrm{HC} \\
\text { bend }\end{array}$ & & & & & 1473 & 13.6 & 1465 & 3.2 & 1474 & 15.7 & 1475 & 14.6 \\
\hline & $\begin{array}{l}\mathrm{HC} \\
\text { bend }\end{array}$ & & & & & 1464 & 0.0 & 1456 & 5.7 & 1464 & 0.0 & 1466 & 0.7 \\
\hline & $\begin{array}{l}\mathrm{HC} \\
\text { bend }\end{array}$ & & & & & 1367 & 0.6 & 1360 & 9.0 & 1372 & 1.1 & 1371 & 0.4 \\
\hline & $\begin{array}{l}\mathrm{HC} \\
\text { bend }\end{array}$ & & & & & 1343 & 4.5 & 1339 & 1.6 & 1348 & 3.7 & 1348 & 2.9 \\
\hline & Torsion & & & & & 1051 & 10.5 & 1060 & 13.1 & 1054 & 11.2 & 1057 & 8.4 \\
\hline & Torsion & & & & & 987 & 4.6 & 976 & 3.0 & 996 & 5.0 & 998 & 6.4 \\
\hline & Torsion & & & & & 951 & 0.0 & 946 & 0.1 & 959 & 0.0 & 962 & 0.2 \\
\hline & Torsion & & & & & 910 & 0.2 & 923 & 0.8 & 915 & 0.4 & 918 & 0.4 \\
\hline & $\begin{array}{l}\text { CSC } \\
\text { assym st }\end{array}$ & & & & & 737 & 0.0 & 743 & 0.1 & 736 & 0.1 & 733 & 0.2 \\
\hline & $\begin{array}{l}\text { CSC } \\
\text { symm st }\end{array}$ & & & & & 684 & 2.4 & 690 & 8.7 & 681 & 2.4 & 679 & 2.4 \\
\hline & $\begin{array}{l}\text { CSC } \\
\text { bend }\end{array}$ & & & & & 260 & 0.1 & 278 & 1.8 & 264 & 0.1 & 264 & 0.7 \\
\hline & Torsion & & & & & 183 & 0.9 & 184 & 10.9 & 191 & 2.8 & 186 & 0.0 \\
\hline & Torsion & & & & & 182 & 0.0 & 182 & 1.4 & 183 & 0.0 & 184 & 2.7 \\
\hline \multirow[t]{6}{*}{ Intermolecular Modes } & & & & & & & & 683 & 41.0 & 508 & 62.2 & 632 & 55.4 \\
\hline & & & & & & & & 268 & 0.2 & 316 & 89.4 & 212 & 26.4 \\
\hline & & & & & & & & 219 & 20.7 & 144 & 4.6 & 139 & 0.6 \\
\hline & & & & & & & & 163 & 16.0 & 47 & 5.3 & 63 & 0.3 \\
\hline & & & & & & & & 61 & 43.7 & 40 & 1.5 & 61 & 7.2 \\
\hline & & & & & & & & & & & & 30 & 2.0 \\
\hline
\end{tabular}

Frequencies are reported in $\mathrm{cm}^{-1}$ and intensities in $\mathrm{km} \mathrm{mol}^{-1}$.

All frequencies reported are calculated at the B3LYP/6-311++G(3df,3pd) level. 
Table 5. Relative Energies of Complexes Studied

\begin{tabular}{|c|c|c|c|c|c|c|}
\hline \multirow{2}{*}{$\begin{array}{l}\text { Complexes } \\
\text { Level of Theory }\end{array}$} & \multicolumn{2}{|c|}{ DMS-HO } & \multicolumn{2}{|c|}{ DMS-OH } & \multicolumn{2}{|c|}{ DMS-HO } \\
\hline & $\mathrm{D}_{\mathrm{e}}$ & $\mathrm{D}_{0}$ & $\mathrm{D}_{\mathrm{e}}$ & $\mathrm{D}_{0}$ & $D_{e}$ & $\mathrm{D}_{0}$ \\
\hline B3LYP/6-31G(d) & 4.9 & 3.5 & 11.3 & 9.2 & 9.2 & 7.6 \\
\hline B3LYP/6-311G(d) & 5.7 & 4.4 & 12.6 & 10.3 & 9.3 & 7.6 \\
\hline $\mathrm{B} 3 \mathrm{LYP} / 6-311++\mathrm{G}(\mathrm{d})$ & 5.2 & 3.9 & 14.1 & 11.8 & 8.3 & 7.0 \\
\hline B3LYP/6-311++G(2d,2p) & 5.0 & 3.7 & 14.3 & 12.0 & 8.3 & 6.9 \\
\hline B3LYP/6-311++G(3df,3pd) & 4.9 & 3.5 & 14.4 & 12.1 & 8.0 & 6.6 \\
\hline UMP2/6-31G(d) & 5.6 & 4.2 & & & 8.9 & 7.3 \\
\hline UMP2/6-311G(d) & 5.4 & 4.1 & & & 8.8 & 7.4 \\
\hline UMP2/6-311++G(d,p) & & & & & 9.1 & 7.7 \\
\hline $\mathrm{UMP} 2 / 6-311++\mathrm{G}(2 \mathrm{~d}, 2 \mathrm{p})$ & & & 8.6 & 6.3 & 9.9 & 8.5 \\
\hline UMP2/6-311++G(3df,3pd) & & & 11.2 & 8.9 & 10.4 & 9.0 \\
\hline PMP2/6-31G(d) & 5.5 & 4.2 & & & 8.9 & 7.4 \\
\hline PMP2/6-311G(d) & 5.4 & 4.1 & & & 8.9 & 7.5 \\
\hline PMP2/6-311++G(d,p) & & & & & 9.2 & 7.8 \\
\hline PMP2/6-311++G(2d,2p) & & & 10.8 & 8.5 & 10.0 & 8.6 \\
\hline PMP2/6-311++G(3df,3pd) & & & 13.5 & 11.2 & 10.5 & 9.1 \\
\hline
\end{tabular}

All energies are reported in $\mathrm{kcal} \mathrm{mol}^{-1}$.

ZPE energy calculated from B3LYP/6-311++G(3df,3pd) frequencies. 
Table 6. Calculated and Experimentally Determined Equilibrium Constant of the DMS-OH Complex at Several Temperatures

\begin{tabular}{|c|c|c|c|c|c|}
\hline \multirow[t]{2}{*}{ Temp (K) } & \multicolumn{3}{|c|}{$\mathrm{K}_{\mathrm{c}}\left(\mathrm{x} 10^{-17}\right)$} & $\mathrm{K}_{\mathrm{c}}\left(\mathrm{x} 10^{-17}\right)$ & \multirow[b]{2}{*}{ PMP2/Exp } \\
\hline & B3LYP $^{1}$ & $\mathrm{PMP}^{2}$ & $\mathrm{MP}^{3}$ & Exp & \\
\hline 215 & 1700 & 220 & 0.94 & & \\
\hline 217 & 1300 & 170 & 0.78 & $26.7^{b}$ & 6.3 \\
\hline 220 & 870 & 120 & 0.58 & & \\
\hline 222 & 670 & 94 & 0.49 & $19.2^{b}$ & 4.9 \\
\hline 225 & 470 & 67 & 0.37 & $14.0^{\mathrm{b}}$ & 4.8 \\
\hline 230 & 260 & 38 & 0.24 & & \\
\hline 235 & 150 & 23 & 0.16 & $10.0^{\mathrm{b}}$ & 2.3 \\
\hline 240 & 85 & 14 & 0.11 & $3.8^{\mathrm{b}}$ & 3.6 \\
\hline 245 & 51 & 8.5 & 0.072 & & \\
\hline 250 & 31 & 5.3 & 0.050 & $2.82^{\mathrm{a}}$ & 1.9 \\
\hline 255 & 19 & 3.4 & 0.035 & $1.43^{\mathrm{a}}$ & 2.4 \\
\hline 258 & 15 & 2.7 & 0.029 & $1.36^{\mathrm{a}}$ & 1.9 \\
\hline 260 & 12 & 2.2 & 0.025 & $0.76^{\mathrm{a}}$ & 2.7 \\
\hline 261 & 11 & 2.1 & 0.023 & $0.58^{\mathrm{a}}$ & 2.2 \\
\hline 265 & 7.8 & 1.5 & 0.018 & & \\
\hline 267 & 6.5 & 1.3 & 0.016 & & \\
\hline 270 & 5.1 & 1.0 & 0.013 & & \\
\hline 275 & 3.4 & 0.69 & 0.0098 & & \\
\hline 280 & 2.3 & 0.48 & 0.0073 & & \\
\hline 285 & 1.6 & 0.33 & 0.0056 & & \\
\hline 290 & 1.1 & 0.24 & 0.0042 & & \\
\hline 295 & 0.76 & 0.17 & 0.0033 & & \\
\hline 298 & 0.62 & 0.14 & 0.0028 & & \\
\hline
\end{tabular}

$\mathrm{K}_{\mathrm{c}}$ is reported in $10^{-17} \mathrm{~cm}^{3}$ molecule $\mathrm{e}^{-1}$.

$\mathrm{MP} 2 / \mathrm{Exp}$ is the ratio $\mathrm{K}_{\mathrm{c}}$ calculated divided by the experimental value.

${ }^{1}$ Calculated using the B3LYP/6-311++G(3df,3pd) energy

${ }^{2}$ Calculated using the PMP2/6-311++G(3df,3pd) energy

${ }^{3}$ Calculated using the MP2/6-311++G(3df,3pd) energy

a Taken from Hynes et al.

${ }^{\mathrm{b}}$ Taken from Barone et al. 


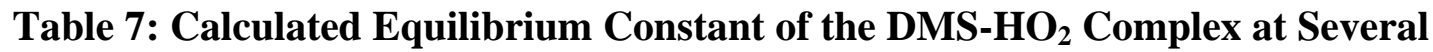
Temperatures

$\begin{array}{lll}\text { Temp }(\mathrm{K}) & \mathrm{K}_{\mathrm{c}}\left(\mathrm{x} \mathrm{10}^{-19}\right)^{1} & \text { Scaled } \mathrm{K}_{\mathrm{c}}\left(\mathrm{x} \mathrm{10}^{-19}\right) \\ 215 & 24 & 7.9 \\ 220 & 15 & 5.0 \\ 225 & 9.7 & 3.3 \\ 230 & 6.5 & 2.2 \\ 235 & 4.3 & 1.5 \\ 240 & 3.0 & 0.99 \\ 245 & 2.1 & 0.69 \\ 250 & 1.5 & 0.49 \\ 255 & 1.1 & 0.35 \\ 260 & 0.76 & 0.25 \\ 265 & 0.56 & 0.19 \\ 270 & 0.42 & 0.14 \\ 275 & 0.31 & 0.11 \\ 280 & 0.24 & 0.080 \\ 285 & 0.18 & 0.061 \\ 290 & 0.14 & 0.047 \\ 298 & 0.096 & 0.032\end{array}$

${ }^{1}$ Calculated using the MP2/6-311++G(3df,3pd) energies 